\title{
LONG-TERM OUTCOME OF STROKES RELATED TO PATENT FORAMEN OVALE. ANALYSIS OF LOCAL POPULATION FROM CODICIA STUDY.
}

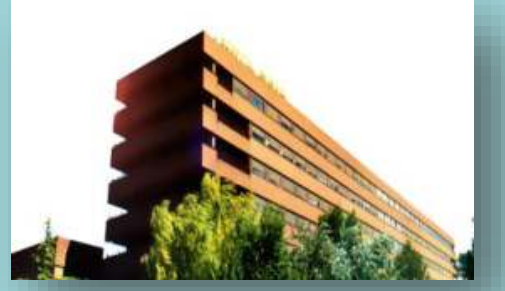

Ayo-Martín O1, Ramos-Araque ME1, Hernández-Fernández F1, García-García J13, Serena J², Segura T12.

1. Neurology Department. Complejo Hospitalario Universitario de Albacete, Universidad de Castilla-La Mancha.

Albacete. Spain.

2. Neurology Department. Hospital Universitario Josep Trueta. Gerona. Spain.

\section{INTRODUCTION}

CODICIA study analysed in 2004 the outcome of patients recruited among 17 Spanish hospitals, suffering an ischemic stroke of undetermined origin. In them, it was studied the functional outcome and probability of relapse, according to the presence of patent foramen ovale (PFO).

Recent trials and metaanalysis reinforces the benefit of PFO closure due to a lower rate of relapses compared to medical treatment. CODICIA study showed that strokes related to PFO use to be non disabling. However, non of those trials analysed the outcome refered as quality of life.

The present study revaluate the outcome in terms of relapse rate and functional status in the sample recruited in our centre in a period longer than 15 years.

\section{GLOBAL DATA}

\begin{tabular}{|r|c|c|c|c|}
\hline $\mathbf{N}=\mathbf{3 0}$ & Global & PFO & No PFO & p \\
\hline Age & 57 & 56 & 58 & NS \\
\hline Sex $(\%$ fem) & 44 & 42 & 47 & NS \\
\hline Hypertension \% & 33 & $\mathbf{8}$ & 53 & $\mathbf{p ~ 0 ' 0 4 5}$ \\
\hline Diabetes \% & 12 & 0 & 19 & NS \\
\hline Smoke \% & 33 & 50 & 47 & NS \\
\hline PFO \% & 44 & & & NS \\
\hline
\end{tabular}

\begin{tabular}{|c|c|c|}
\hline \multicolumn{3}{|c|}{ Outcome in PFO patients } \\
\hline Relapses & mRankin $\mathbf{0 - 1} \%$ & $\mathrm{p}$ \\
\hline Yes & 56 & NS \\
\hline No & 42 & NS \\
\hline
\end{tabular}

\section{MATERIAL AND METHODS}

The study included patients aged $>18$ years, with recent cryptogenic ischemic stroke or TIA (TOAST criteria). A transcranial Doppler was done for determining the presence of right-to-left shunt, following the standardised guidelines. The present study followed up the patients recruited in our centre and record the presence of relapses and good functional status (0-1 points in mRankin scale) in 2017.

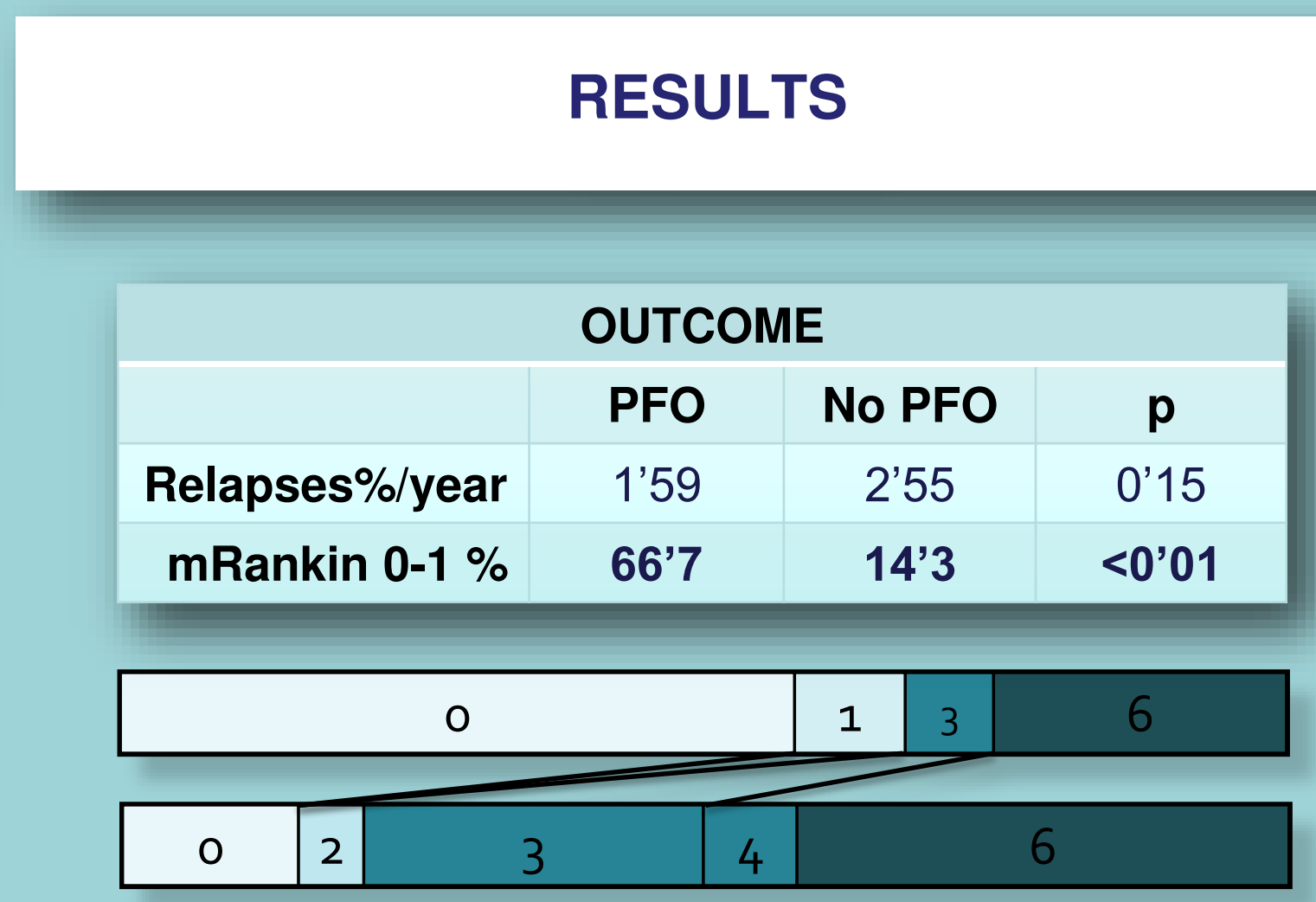

Multivariate analysis mRankin $0-1 \%$

OR $\quad p$

PFO 2'48 (1'76-81'8) $\quad 0$ '01

Hypertension - $\quad$ NS

\begin{tabular}{l|l|l} 
Smoke & - & NS
\end{tabular}

Basal mRankin $\quad$ - NS

\section{CONCLUSIONS}

This substudy reinforces the idea that patients with PFO have a very favourable prognosis, even in the few cases with relapses. This should redefine the benefit of closing the patent foramen ovale, which is expensive and is not free from risks. This hypothesis has recently reinforced in the new guidelines. 